\title{
Jean-Baptiste Baronian, Rimbaud
}

\section{Maria Emanuela Raffi}

\section{(2) OpenEdition}

\section{Journals}

\section{Edizione digitale}

URL: http://journals.openedition.org/studifrancesi/6988

DOI: 10.4000/studifrancesi.6988

ISSN: 2427-5856

\section{Editore}

Rosenberg \& Sellier

\section{Edizione cartacea}

Data di pubblicazione: 1 septembre 2010

Paginazione: 396

ISSN: 0039-2944

\section{Notizia bibliografica digitale}

Maria Emanuela Raffi, «Jean-Baptiste Baronian, Rimbaud», Studi Francesi [Online], 161 (LIV | II)| 2010,

online dal 30 novembre 2015, consultato il 10 janvier 2021. URL: http://journals.openedition.org/

studifrancesi/6988 ; DOI: https://doi.org/10.4000/studifrancesi.6988

\section{Questo documento è stato generato automaticamente il 10 janvier 2021.}

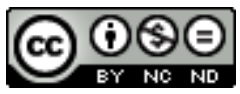

Studi Francesi è distribuita con Licenza Creative Commons Attribuzione - Non commerciale - Non opere derivate 4.0 Internazionale. 


\title{
Jean-Baptiste Baronian, Rimbaud
}

\author{
Maria Emanuela Raffi
}

\section{NOTIZIA}

JEAN-BAPTISTE BARONIAN, Rimbaud, Paris, Gallimard, 2009, pp. 286.

1 Si segnala la pubblicazione, nella collezione «Folio biographies», di questa 'vivace' biografia di Rimbaud, costruita su un tessuto di fatti, avvenimenti, incontri, lettere e testi che ritracciano in una fitta interazione, e in una tonalità concreta, quotidiana e a tratti quasi intima, una delle più straordinarie esistenze della storia letteraria. Ne risulta un ritratto ricco di sfumature anche contrastanti, circondato da numerosi altri ritratti, a partire da quello di Mme Rimbaud quintessenza della "tyrannie domestique", per continuare con Izambard, Delahaye, Ernest Cabaner, Eugène Vermersch, Isabelle Rimbaud e molti altri. Lettura certo non scientifica ma appassionante, con passaggi quasi commoventi: quelli che riguardano, ad esempio, la lunga amicizia fra Rimbaud e Delahaye. 